\title{
Shear Strength of Die Attachments Prepared Using Dry Nanosilver Film by a Time-Reduced Sintering Process
}

\author{
Jingru Dai ${ }^{\mathrm{a}}$, Jianfeng $\mathrm{Li}^{\mathrm{b}}$, Pearl Agyakwa ${ }^{\mathrm{a}}$, Martin Corfield ${ }^{\mathrm{a}}$ and Christopher Mark Johnson ${ }^{\mathrm{a}}$ \\ ${ }^{a}$ Department of Electrical and Electronic Engineering, University of Nottingham, Nottingham, University Park, NG7 2RD, UK. \\ ${ }^{\mathrm{b}}$ Zhuzhou CRRC Times Electric UK Innovation Centre, Birmingham Business Park, Solihull, B37 7YE, UK.
}

\begin{abstract}
This study investigates a time-reduced sintering process for die attachment, prepared, within a processing time of several seconds using dry nanosilver film. The effects of three main sintering parameters, sintering temperature $\left(220\right.$ to $\left.300{ }^{\circ} \mathrm{C}\right)$, sintering time $(1$ to $9 \mathrm{~s}$ ) and bonding pressure (6 to $25 \mathrm{MPa}$ ) on the resultant shear strength are investigated using uniform design and single factor experimental trials. The shear strength data series for each of the experimental trials was statistically analyzed to indicate any deviation from normal distribution. The resulting shear strength values were regressed or fitted, and further analyzed by polynomial and kinetic-like equations to estimate the relationship between the shear strength and sintering parameters. The regression analysis for shear strength may not only be used for explaining mass transportation mechanisms, but also for identifying the proposed manufacturability of the time-reduced sintering process.
\end{abstract}

\section{Index Terms}

Time-reduced sintering, nanosilver film, shear strength, sintering mechanisms, and manufacturability

\section{INTRODUCTION}

With increasing demand for high power density and high performance power electronics systems, conventional Sn-based solders are no longer considered acceptable for power die attachments or other interconnects where the operating temperature s are expected to rise above $175^{\circ} \mathrm{C}$. The use of high lead solders with a $\mathrm{Pb}$ content of $85-97$ wt.\% is a standard and widely accepted approach for improving the reliability of conventional Sn-Ag solder joints [1]. However, lead is restricted in the application of electronics packaging owing to environmental concerns. Among the limited lead-free high temperature solder candidates, Au-based and $\mathrm{Zn}-\mathrm{Al}$ solders are considered either cost-ineffective or exhibit poor processing performance [2,3]. Silver sintering is therefore considered to be one of the most promising lead-free alternatives; since the sintering process can be carried out at temperatures comparable to those used for $\mathrm{Sn}$-based reflow soldering processes, whereas possessing high electrical and thermal conductivity and high reliability, in comparison to existing solders. The superior thermal performance and reliability of sintered die attachment for high temperature power electronic applications has been demonstrated previously in [4], where the increase in the thermal resistance increase was found to be less than a tenth of the thermal resistance increase of a corresponding Pb5Sn soldered die attachments under a power cycling test with a temperature swing of 50 to $175^{\circ} \mathrm{C}$.

Schwarzbauer $[5,6]$ first proposed the use of pressureassisted sintering technology for attaching electronic devices in 1989 , where a sintering temperature below $300^{\circ} \mathrm{C}$ and a high bonding pressure of 30 to $50 \mathrm{MPa}$ were used to form robust sintered joints produced within a few minutes. However, the employment of high bonding pressure during sintering complicates the sintering process, and makes it less feasible in practice. In 2002, Zhang and Lu [7] made significant progress in the silver sintering process by replacing the micro-scaled silver particles with nanosilver particles, allowing sintering to take place at temperatures lower than $275{ }^{\circ} \mathrm{C}$ and under pressures of only a few $\mathrm{MPa}$, or even pressureless to prepare robust sintered Ag joints. Since then, numerous parameter studies have been carried out to improve or simplify the silver sintering process [8-10].

The formulation of silver paste, substrate conditions and sintering parameters influence the bonding quality, where different bonding/sintering mechanisms are underlying [11]. Akada, et al. [12] discussed the bonding mechanism of silver metal-organic nanoparticles, and concluded that the decomposition or removal of the organics in the silver paste is necessary to achieve desirable or robust sintered joints. Wereszczak, et al. [13] revealed the effects of the topography of bonding surfaces and paste patterns in relation to the bonding 
strength of sintered joints. Buttay, et al. [14] also concluded that surface roughness has a significant effect on the re-productivity of sintered die attachments where high surface roughness of substrates could cause poor adhesion quality due to the formation of large voids at the interfaces. Mei, et al. [10] and Xiao, et al. [9] found that joints with shear strength above 30 MPa can be obtained by applying a low pressure during the drying stage before carrying out sintering at $275^{\circ} \mathrm{C}$ for $10 \mathrm{~min}$.

It has been demonstrated that different combinations of sintering parameters can produce sintered joints with comparable shear strengths or microstructural porosity $[15,16]$. From the perspective of manufacturability, low sintering temperatures, low (or zero) pressures and short sintering times are preferable in terms of improved manufacturing efficiency, low cost, ease of implementation, as well as reduced thermomechanical stress/strain within the assembly, either during the sintering process or in service [17]. However, the time-reduced sintering or more time-efficient sintering processes have seldom been considered. This is perhaps because the general sintering equipment most commonly used (e.g. hydraulic press) are somewhat limited in that they require the simultaneous and inextricable application of heat and load, typically on the basis of one die/substrate each time [18]. The times recommended even for pressure-assisted sintering of nanosilver are still of an order of several minutes, and the long processing times can compare poorly with standard reflow processes where multiple parts can be processed in parallel on one piece of equipment in under several minutes. Lengthy processing times for silver sintering is still considered one of the main factors restricting its use in general applications. However, there is relatively few literature available on the sintering behavior and reliability of sintered joints, by a time-reduced sintering process. The authors' previous study [19] has shown that the power cycling reliability of sintered joints prepared using a sintering time of 5 $\mathrm{s}$ is comparable to those for sintered joints prepared using a sintering time of $5 \mathrm{~min}$ by a conventional sintering route.

In addition, dry film of Ag nanoparticles has been developed for much more efficient sintering processes. Unlike wet nanosilver pastes, the amount of organics in dry nanosilver film has been significantly reduced, thus eliminating the requirement for a drying step. During the sintering process, the dry film is rapidly transferred onto the back side of a power device, and then placed on the substrate. However, the sintering behavior of dry nanosilver film needs further investigation and the impact of the lower amounts of organics on the microstructure and resultant properties of sintered joints must be determined.

This study is primarily concerned with a time-reduced sintering process using a commercially available dry nanosilver film, an automatic die pick-and-place machine and a short processing time of several seconds (less than $12 \mathrm{~s}$ ) for each joint. The shear strength dependencies on the main sintering parameters; sintering temperature, pressure and time were analyzed by either polynomial or kinetic-like equations. These equations were used not only to reveal different mechanisms dominating the shear strength of the sintered joints, but also to draw processing windows of sintering parameters for timereduced sintering of nanosilver film for attaining desirable shear strengths.

\section{EXPERIMENTS AND METHODS}

\subsection{Materils and Sample Preparation}

A nanosilver dry film, Argomax 2020 was obtained from Alpha Assembly Solutions. The film is suitable for pressureassisted sintering where the bonding surfaces of the substrates are finished with Ag or Au. Dummy silicon dies of $2 \mathrm{~mm} \times 2$ $\mathrm{mm} \times 0.5 \mathrm{~mm}$ were obtained from Dynex Semiconductor Ltd. They have $\sim 0.7 / 0.5 \mu \mathrm{m}$ thick Ni/Ag metallization on the back side and $\sim 5 \mu \mathrm{m}$ thick Al metallization on the top side. AlN substrates were custom-manufactured from DOWA Metaltech Co., Ltd. They consist of $1 \mathrm{~mm}$ thick AlN ceramic tile with 0.3 $\mathrm{mm}$ thick $\mathrm{Cu}$ on both sides, with $0.2 \mu \mathrm{m}$ thick silver on the top $\mathrm{Cu}$ metallization.

The sintering process was controlled by a Datacon 2200 EVO die bonder. A vacuum pickup-and-place tool was first preheated to $130{ }^{\circ} \mathrm{C}$. The die was then picked up, aligned and dropped onto a piece of nanosivler film matrix to transfer film onto the backside of the die. The die and film were then placed onto a substrate which had been pre-heated to the sintering temperature. As the die touched down, the tool temperature rapidly reaches the sintering temperature, while a force of up to $10 \mathrm{~kg}$ is simultaneously applied. After the completion of the die attachment, the tool is rapidly cooled to $130^{\circ} \mathrm{C}$ within $6-10 \mathrm{~s}$ before carrying out the next sintering operation in a production process. In this study, a total of 18 dies were attached onto the same substrate, as is shown in Fig.1.

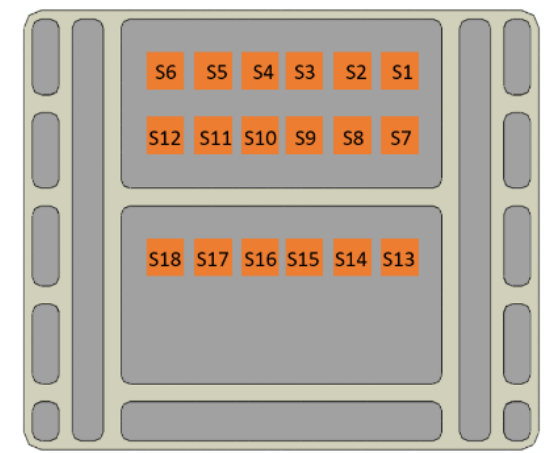

Fig. 1. Layout of 18 dies of $2 \mathrm{~mm} \times 2 \mathrm{~mm}$ attached on the same substrate using the same sintering parameters (the dimension of die is not to scale).

\subsection{Die Shear Strength Test and Characterization}

Shear strength tests were performed on a Nordson DAGE 4000 Plus bond tester (Buckinghamshire, UK) at a constant shear rate of $0.2 \mathrm{~mm} / \mathrm{s}$, with a shear height of $180 \mu \mathrm{m}$. The statistical distribution and average shear strength were obtained from 18 die attachments on the substrate where the error is estimated to be within $0.25 \%$. In addition, the fractured surfaces of sintered joints after die shear tests were characterized using a Hitachi TM3000 desktop Scanning Electronic Microscope (SEM, Hitachi High-Tech, Minato-ku, 
Tokyo 105-8717, Japan) to observe microstructural morphologies within the sintered Ag joints.

\subsection{Statistical Experimental Design}

In this study, a uniform design of experiments together with single factor design methodology is used to investigate the time-reduced sintering process using nanosilver film. The uniform design is capable of optimizing sintering parameters with fewest tests rather than just illuminating the effect of independent variables on the shear strength as the single factor analysis method does. It responds well even when there is no precise knowledge about the underlying regression models derived from the independent variables [20, 21]. A detailed description about the uniform design method can be found in [20, 22]. According to Draper and Smith [23], whether a regressed equation is statistically significant is judged from the confidence level determined by the $\mathrm{F}$ test. The predictive precision of the regressed equation is determined from the residual mean square value [24].

For experimental design, the critical sintering parameters consist of sintering temperature (T) of 220 to $300{ }^{\circ} \mathrm{C}$, sintering time (t) of 1 to $9 \mathrm{~s}$ and sintering pressure $(\mathrm{P})$ of 6 to $25 \mathrm{MPa}$. Each of the three parameters were designed with 5 levels and a total of 9 trials arranged according to the specified uniform table U9 (53). In addition, another 12 experimental trials for single factor design and 6 additional trials (not included in the singlefactor design) were also carried out. The results from all the experimental trials were combined together to increase the statistical significance when regressed and fitted to mathematical models, described later. Table I lists all the experimental trials consisting of different combinations for sintering temperature, sintering time and pressure.

\subsection{Polynomial Models}

A polynomial expression is used to describe the effects of sintering parameters on the bonding strength of the sintered joints prepared by a time-reduced sintering process. A firstorder polynomial or a second-order polynomial model for the bonding strength can be expressed as:

$$
F(P, T, t)=a_{0}+a_{1} P+a_{2} T+a_{3} t+a_{4} P T+a_{5} P t+a_{6} T t+a_{7} P^{2}+a_{8} T^{2}+a_{9} t^{2}(1)
$$

where $\mathrm{F}(\mathrm{P}, \mathrm{T}, \mathrm{t})$ is the shear strength, $\mathrm{P}, \mathrm{T}$ and $\mathrm{t}$ stand for the sintering pressure, temperature and time, respectively, and a0, $\mathrm{a} 1, . ., \mathrm{a} 9$ are empirical constants. Once the data for shear strength (from all the experiments) are obtained, the polynomial equation can be established by using regression analysis. In this analysis method, the items that are statistically significant to shear strength are retained in the polynomial regression, whereas the ones that are considered as a negligible influence are filtered using stepwise regression [25].

\subsection{Kinetics-like Models}

To provide insight into the relevant material mechanisms during the time-reduced sintering process, a kinetic like model, Eq. (2), similar to those describing the sintering kinetics of powder compacts $[26,27]$, is proposed to describe the effects of sintering temperature, time and pressure on the average bonding strength of the joints. It is considered that shear strength is associated with mass transportation, causing grain growth, intergranular interactions and densification.

$$
F=b P^{\gamma} \exp \left(-\frac{E}{R T}\right) t^{\varepsilon}
$$

In Eq. (2), $R$ and $T$ are the universal gas constant and absolute temperature in Kelvin; $b, \gamma, \varepsilon, E$, related to material transportation mechanisms, are constants determined through data fitting of the experimental results to Eq. (2). The values of $\gamma, \varepsilon$, and $E$ can be used to evaluate the sintering mechanisms that govern the densification for shear strength. It should be noted that it is Eq. (2) rather than any expressions similar to Herring's scaling law that has been employed. This is because the effects of the sintering parameters on the shear strength are non-linear, as will be illustrated by the shear strength values shown later. In addition, the nanosilver film cannot be bonded onto the substrate (its thickness remains constant with no densification) if no bonding pressure is applied during sintering. Therefore, an exponential dependence on the bonding pressure relationship was chosen for shear strength. 
TABLE I. EXPERIMENTAL TRIALS CONSISTING OF DIFFERENT COMBINATIONS OF SINTERING TEMPERATURE, TIME AND PRESSURE.

\begin{tabular}{|c|c|c|c|}
\hline Trial & $\begin{array}{c}\text { Sintering temperature } \\
\mathrm{T},{ }^{\circ} \mathrm{C}\end{array}$ & $\begin{array}{c}\text { Sintering time } \\
t, s\end{array}$ & $\begin{array}{c}\text { Bonding pressure } \\
\mathrm{P}, \mathrm{MPa}\end{array}$ \\
\hline $\mathrm{Tb}$ & 250 & 5 & 10 \\
\hline $\mathrm{T} 1$ & 240 & 5 & 10 \\
\hline $\mathrm{T} 2$ & 260 & 5 & 10 \\
\hline $\mathrm{T} 3$ & 280 & 5 & 10 \\
\hline $\mathrm{T} 4$ & 300 & 5 & 10 \\
\hline P1 & 250 & 5 & 6 \\
\hline $\mathrm{P} 2$ & 250 & 5 & 15 \\
\hline $\mathrm{P} 3$ & 250 & 5 & 20 \\
\hline P4 & 250 & 5 & 25 \\
\hline $\mathrm{t} 1$ & 250 & 1 & 10 \\
\hline $\mathrm{t} 2$ & 250 & 3 & 10 \\
\hline $\mathrm{t} 3$ & 250 & 5 & 10 \\
\hline $\mathrm{t} 4$ & 250 & 7 & 10 \\
\hline U1 & 240 & 6 & 25 \\
\hline U2 & 300 & 7 & 12.5 \\
\hline U3 & 280 & 4 & 6 \\
\hline U4 & 230 & 8 & 7.5 \\
\hline U5 & 220 & 3 & 17.5 \\
\hline U6 & 290 & 2 & 22.5 \\
\hline $\mathrm{U} 7(\mathrm{t} 1)$ & 250 & 1 & 10 \\
\hline U8 & 260 & 5 & 15 \\
\hline U9 & 270 & 9 & 20 \\
\hline V1 & 220 & 1 & 25 \\
\hline V2 & 220 & 5 & 25 \\
\hline $\mathrm{V} 3$ & 220 & 9 & 25 \\
\hline W1 & 220 & 1 & 6 \\
\hline W2 & 260 & 6 & 10 \\
\hline W3 & 300 & 9 & 19.5 \\
\hline
\end{tabular}

\section{RESULTS}

\subsection{Statistical Distribution}

Statistical analysis was applied to the data series of the shear strength for each of the experimental trials. The purpose was to evaluate whether the 18 shear strength values obtained from the same substrate showed any deviation from a normal distribution. In particular, we were interested to ascertain whether the die attachments produced earlier in the process and therefore subjected to a longer (pressure-less) heat treatment, as a result of substrate heating, have differing shear strength values compared to those produced later in the process. The results of the statistical analysis would therefore help to understand whether cumulative pressure-less heat treatments may have an effect on the distribution of shear strengths of sintered joints on the same test coupon.

Statistical analysis of shear strength values for 13 singlefactor design experimental trials have been reported in our previous paper [28], showing that the shear strength data series obeyed a normal distribution with a confidence level higher than 0.94. Similar results have also been achieved for the uniform design experimental trials U1 to U9 and additional six trials V1 to W3. Fig. 2 presents the cumulative probability curves for the shear strength data series from the uniform design experimental trials and additional trials, respectively. Therefore, the values and variations of the shear strength from all experiments in this study are compared using their mean and standard deviations (SDs).
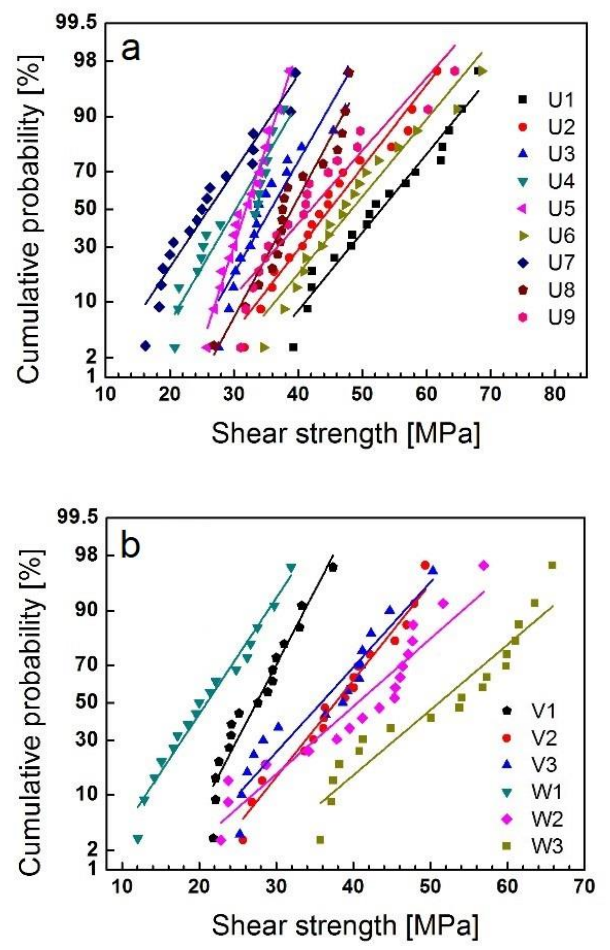

Fig. 2. Cumulative probability curves of shear strength data series from: (a) uniform design experiments, and (b) additional experimental trials.

\subsection{Shear Strength values}

The mean and SDs of shear strength values from all the 27 experimental trials have been reported in [29]. The average shear strength values are in the range of 26.1 to $52.9 \mathrm{MPa}$, with a maximum SD of $15.18 \%$. The lowest shear strength value of 26.1 MPa was obtained from the sintered joints prepared using the shortest sintering time of $1 \mathrm{~s}$, sintering temperature of 250 ${ }^{\circ} \mathrm{C}$ and bonding pressure of $10 \mathrm{MPa}$ (Trial t1). Conversely, the highest shear strength value of $52.9 \mathrm{MPa}$ was achieved using a bonding pressure of $25 \mathrm{MPa}$ (maximum pressure), sintering temperature of $240{ }^{\circ} \mathrm{C}$ and sintering time of $6 \mathrm{~s}$. As reported in [28], the SD variation somewhat increases with increasing sintering temperature and time, whereas it is relatively insensitive to bonding pressure, as observed from the single factor design experimental trials. The average shear strength appears to increase with increasing sintering temperature, time and pressure, within the scope of sintering parameters considered. 


\subsection{Mathematical Equations}

\subsubsection{Polynomial Equations}

The average shear strength values for all the 27 experimental trials have been regressed into first-order polynomial and second-order equations using stepwise regression method. The regression results are given by Eq. (3) and Eq. (4), respectively.

$$
\begin{gathered}
F=1.96 \times 10^{-1} T+1.19 t+6.86 \times 10^{-1} P-28.2 \\
F=1.98 \times 10^{-1} T+3.41 t-2.12 \times 10^{-1} t^{2}+2.24 \times 10^{-2} P^{2}-29.3
\end{gathered}
$$

The variance for the regression analysis showed that both the first-order and second order polynomial equations for shear strength are statistically significant with confidence levels higher than 0.99 [29]. However, prediction precisions of \pm 3.1 $\mathrm{MPa}$ and $\pm 6.2 \mathrm{MPa}$ for the second-order equation, Eq. (4), at a probability approximately of 0.68 and 0.95 compares with the prediction precisions of $\pm 3.5 \mathrm{MPa}$ and $\pm 7 \mathrm{MPa}$ for the firstorder equation, Eq. (3), at a probability approximately of 0.68 and 0.95 respectively. Considering the higher prediction accuracy of the second-order polynomial equation, the values derived from Eq. (4) were chosen for comparison with the experiment results [29]. The maximum relative error between the experimental results and the regressed model is $15.16 \%$ observed with Trial V1, among all the 27 experimental trials.

\subsubsection{Kinetic-like Equation}

The results of data fitting tested shear strength values from the 27 experimental trials to the kinetic-like equation presented in Eq. (2) is given below. The constants in Eq. (2) are determined using nonlinear least square optimization with a Matlab function of multidimensional unconstrained nonlinear minimization, fminsearch, described in [29].

$$
F=161.24 P^{0.26} \operatorname{EXP}\left(-10.35 \times 10^{3} / R T\right) t^{0.14}
$$

The variance analysis shows that the kinetic-like equation for shear strength, is statically significant with a confidence level higher than 0.99 [29]. The shear strength values calculated from Eq. (5) have been compared with the experimental values. The relative error for the shear strength values predicted from Eq. (5) are from -18.6 to $17.13 \mathrm{MPa}$. The prediction precision is $\pm 3.5 \mathrm{MPa}$ and $\pm 7.0 \mathrm{MPa}$ at a probability approximately of 0.68 and 0.95. However, in comparison with those of the corresponding second-order polynomial equation (4), the results of the kinetic-like equation, (5), have somewhat higher relative errors and poorer prediction precision.

\section{DISCUSSION}

\subsection{Comparison with Existing Results}

The range of experimentally tested shear strength values, 26.1 to $52.9 \mathrm{MPa}$, is comparable with those of sintered joints prepared using conventional sintering of wet nanosilver paste, where the sintering times are longer than 5 minutes [18, 30, 31]. The present minimum shear strength of $26.1 \mathrm{MPa}$ (obtained by trial t1) using a sintering temperature of $220{ }^{\circ} \mathrm{C}$, a sintering pressure of $6 \mathrm{MPa}$ and a sintering time of $1 \mathrm{~s}$ is still comparable with those of Pb5Sn solder joints (18 to $25 \mathrm{MPa}$ ) and Au12Ge joints ( 25 MPa) [32-35]. The high shear strength values for sintered joints prepared by the time-reduced sintering process may be ascribed to the following two facts: (1) there is a smaller amount of organics in the dry nanosilver film which accelerates the sintering of silver nanoparticles and (2) a pre-bonding pressure of $3 \mathrm{MPa}$ is applied when the nanosilver film is transferred onto the die backside, which has been reported to improve the shear strength of sintered joints [10].

In the present work, the effects of sintering parameters on the shear strength have been regressed or fitted to both polynomial and kinetic-like equations. From both variance analysis and comparison with experimental values, second-order polynomial equations have a higher statistical estimation than the corresponding kinetic-like equation. Such a result may be attributed to the following fact. A polynomial function with sufficient terms can be used to describe any complicated relationship with dependent variables. The present secondorder polynomial equation reflects the dominant effects of sintering parameters on the shear strength. These effects take into account all the relevant mechanisms despite the fact that the physical mechanisms themselves are not yet established. By contrast, kinetic-like equations are based on the assumed physical mechanisms of mass transportation occurring during the sintering process and disregard other mechanisms/factors which may have some impact on the shear strength. For example, all the sintered samples were prepared with commercially available AlN-based substrates which have typical surface roughness parameters $R_{a}$ of $1.218 \mu \mathrm{m}$ and $R_{z}$ of $8.847 \mu \mathrm{m}$, indicating a certain range of variation in the substrate surface conditions for the sintered joints in the different trials. This would have an impact on the distribution of external pressure applied on die attachments during sintering, which is not taken into consideration in the kinetic-like equation for shear strength.

In previous work on the conventional sintering of nanosilver paste where the sintering parameters included paste drying times of between 10 to $45 \mathrm{~min}$, sintering temperatures between 240 to $300{ }^{\circ} \mathrm{C}$, sintering times of 1 to $8 \mathrm{~min}$ and pressures of 1 to $15 \mathrm{MPa}$, only polynomial equations were used to regress the effects of the sintering parameters on the shear strength of the attachments [18]. There was no term for sintering time in the regressed equation, and hence its effect on the shear strength was considered negligible. Such a result is actually in good agreement with the present result for the time-reduced sintering process. This is because according to the present second-order equation, the rate of increase in the shear strength with increasing sintering time is gradually decreased and the shear strength appears to be stable when the sintering time is longer than $\sim 8 \mathrm{~s}$ which is much shorter than the time of 1 min reported in previous work [18]. This is further supported by the fact that there is notable change in shear strength for 5 to 30 min-sintered joints when sintering temperature increases from 200 to $350{ }^{\circ} \mathrm{C}$ under a bonding pressure of $5 \mathrm{MPa}$ [31].

On the other hand, the effects of sintering temperature and pressure on the shear strength was more convoluted in previous work [18]. In that work, the shear strength dependence on bonding pressure was associated with the applied sintering 
temperature. For a lower sintering temperature (e.g. $\left.240{ }^{\circ} \mathrm{C}\right)$, the average shear strength increased with sintering pressure, from 1 to $11 \mathrm{MPa}$ at which point it remained relatively constant as the sintering pressure increased to $15 \mathrm{MPa}$. For higher sintering temperatures (e.g. $300^{\circ} \mathrm{C}$ ), the average shear strength also increased with comparable sintering pressures from 1 to 10 MPa but then slightly decreased with further increases in the sintering pressure to $15 \mathrm{MPa}$. The maximum shear strength of $54.9 \pm 3.0 \mathrm{MPa}$ was obtained by using a sintering temperature of $240{ }^{\circ} \mathrm{C}$ and a sintering pressure of $12.5 \mathrm{MPa}$. Such results can be ascribed to the fact that the effective densification due to atomic diffusion and particle consolidation in the different experimental trials might all be completed within one minute, and rapid growth and coalescence of $\mathrm{Ag}$ nanoparticles at both higher sintering temperatures and bonding pressures might lead to relatively poor re-arrangement of the Ag particles during the final sintering stage. In the present work, the sintering time was significantly reduced to a few seconds, and therefore sintering temperature and pressure predominately influence the bonding quality of the sintered joints. The regressed second-order polynomial equation reflects the fact that the shear strength increases with both increasing sintering temperature and pressure across the scope of sintering parameters used in this study. The explanation for this is that the effective densification due to atomic diffusion and particle consolidation in the present experiments have consolidated within the short sintering time of 1 to $9 \mathrm{~s}$, where increasing the temperature and/or bonding pressure accelerates the driving force (increase in surface energy and real contacts between particles) for sintering.

\subsection{Effect of Sintering Temperature}

Figure 3 plots shear strength against sintering temperature derived from the second-order polynomial, (4) and the kineticlike equation, Eq. (5) under different sintering pressure at a sintering time of $5 \mathrm{~s}$, together with the experimental values for the corresponding single factor experimental trials. As shown in Figure 3, the shear strength predicted from both equations indicates that the shear strength increases with increasing sintering temperature, which is in good agreement with the experimental values of shear strength from the single factor trials.

Despite the comparatively higher degree of uncertainty, the kinetic-like equation for shear strength can be used to provide insight into the relevant mechanisms dominating the effects of sintering temperature on the shear strength with a high confidence level. While they may have low predictive precision locally, it can still reflect dominating mechanisms globally. According to the kinetic-like equation, Eq. (5), the shear strength dependency on the sintering temperature has an activation energy of $10.35 \mathrm{~kJ} / \mathrm{mol}$; this value is much lower than that reported for either lattice diffusion (130 to $171 \mathrm{~kJ} / \mathrm{mol})$ grain boundary diffusion ( 45 to $92 \mathrm{~kJ} / \mathrm{mol}$ ) or plastic flow (78 $\pm 3 \mathrm{~kJ} / \mathrm{mol}$ ) of silver [36-39]. However, it is similar to the activation energy for self-diffusion in liquid $\mathrm{Sn}$ (10.725 to 11.59 $\mathrm{kJ} / \mathrm{mol}$ ) and the molten channel controlled intermetallic growth of a $\mathrm{Ni}_{3} \mathrm{Sn}_{4}$ layer for $\mathrm{Sn}-3.5 \mathrm{Ag}$ solder during liquid-phase reactions $(12.214 \mathrm{~kJ} / \mathrm{mol})$ [40-42]. It is considered that the relatively low activation energy may be related to liquidassociated diffusion such as local surface-melting of nanoscaled silver particles.
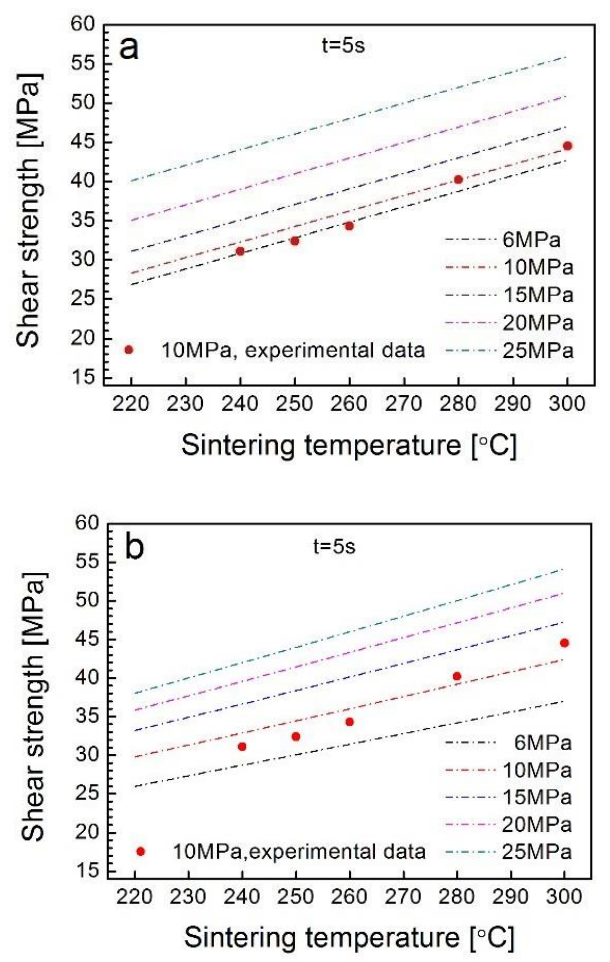

Fig. 3. Plots of average shear strength versus sintering temperature predicted from the second order polynomial equation (4) for the sintering time of $5 \mathrm{~s} \mathrm{(a),}$ and the kinetic-like equation (5) for the sintering time of $5 \mathrm{~s}(\mathrm{~b})$, together with the experimental points of the corresponding single factor trials.

It is reported that the melting point becomes lower when the particle size is reduced to nanoscale size, where the particle surface may melt at lower temperatures due to the presence of shorter diffusion pathways [43, 44]. Together with the application of pressure, the diffusion path/interface can be further reduced where nanosilver particles coalesce, which is likely to result in narrow channels between silver particles or near the grain boundaries. Thus, the diffusion of silver through the narrower channels enhances the mass transportation. In other words, the application of bonding pressure reduces the influence of temperature dependence on the mass transportation process. This hypothesis is further supported by a study which treated the sintering of $\mathrm{Ag}$ nanoparticles as a liquid-phase phenomena [45]. The development of local surface melting areas can lead to the transfer of densification mechanisms to either grain boundary diffusion or plastic diffusion [46]. Grain boundary diffusion and plastic diffusion may still dominate the densification of silver but with a lower activation energy than that observed in the sintering of large $\mathrm{Ag}$ particles [33]. It shows that the grain size in a denser joint prepared at a high sintering temperature is evidently larger than that for a less dense one formed at a lower temperature, see Fig. 4. 


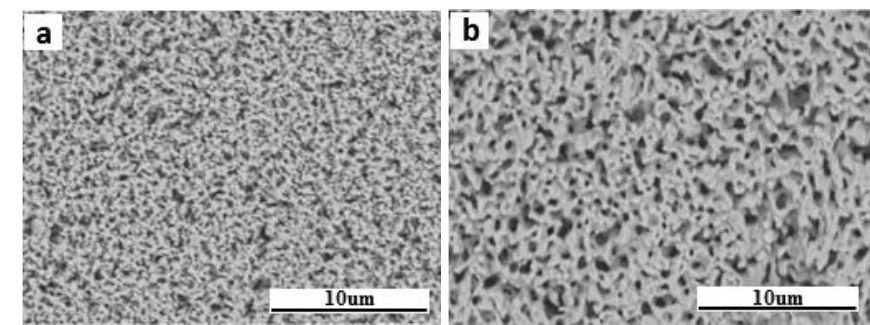

Fig. 4. SEM images of fracture surfaces of sintered samples obtained from: (a) Trial T1 at $240{ }^{\circ} \mathrm{C}$; and (b) Trial $\mathrm{T} 4$ at $300{ }^{\circ} \mathrm{C}$.

The mass transportation mechanism of particle surface melting is mainly dependent on sintering temperature. It is believed to result in high density and contributes to high shear strength when the sintering temperature is high enough [47]. For a given low temperature range, surface diffusion dominates mass transfer, but it is a non-densifying mechanism, which consumes the driving force/energy required for further densification without bringing a potential increase in shear strength. In particular, surface diffusion is actually enhanced at lower temperatures due to the large surface to volume ratio of the Ag nanoparticles. More importantly, the mechanisms of mass transportation for promoting the adhesion of the silver particles to the bonding surface of substrates are mainly responsible for the shear strength of joints produced by timereduced sintering.

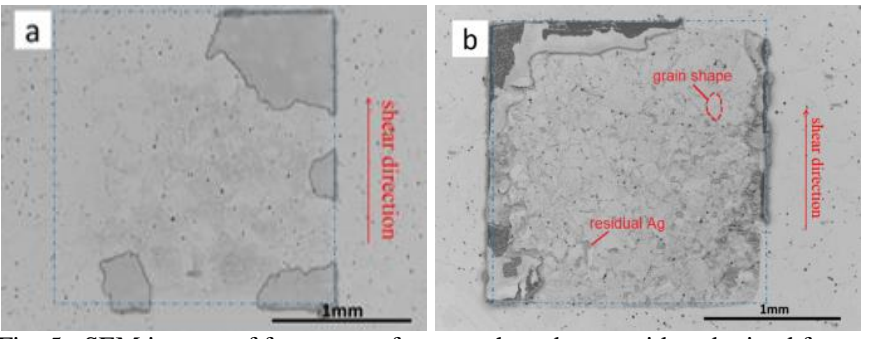

Fig. 5. SEM images of fracture surfaces on the substrate sides obtained from samples of: (a) Trial $\mathrm{T} 1$ at $240{ }^{\circ} \mathrm{C}$ with a shear strength of $31.1 \mathrm{MPa}$; and (b) Trial T4 at $300{ }^{\circ} \mathrm{C}$ with a shear strength of $44.5 \mathrm{MPa}$.

According to fracture surface observations, nearly all samples with lower shear strength (e.g. below $30 \mathrm{MPa}$ ) failed at the interface between the substrate and the sintered layer. Furthermore, sintered joints with higher shear strength displayed strong bonding between the substrate and the sintered layer, as is evident from the fracture surfaces, where an amount of residual Ag appears on the bonding substrate side, see Fig.5. There is also evidence that the fracture occurred from the neck regions of small Ag particles (in diameters of sub-micron meters) at the substrate/sintered layer interface, which is considered to be the weak interconnection point, see Fig.6. Plastic diffusion/flow is considered to be the main sintering mechanisms associated with the interactions of $\mathrm{Ag}$ at the substrate/sintered layer interface. It primarily controls the early stage sintering of silver particles, as it does not need any thermal activation. Plastic flow is closely associated with the pressure applied, which serves to reduce the diffusion pathways between Ag particles and increases the driving force for sintering. Once some degree of shrinkage or necking has occurred, thermally- induced mechanisms such as surface diffusion and grain boundary diffusion dominate.

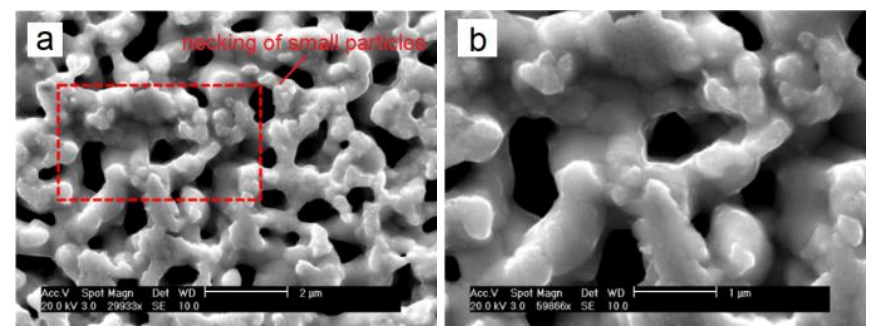

Fig. 6. SEM images of fracture surface obtained from sample of Trial U2 with a shear strength of $44.9 \mathrm{MPa}$ (similar to sample of Trial T4). (b) is the enlarged field view of the area boxed by red dash lines in (a).

\subsection{Effect of Sintering Time}

Figure 7 shows the effect of sintering time on the shear strength predicted from the second-order polynomial equation, Eq. (4), and the kinetic-like equation, Eq. (5), under different sintering temperatures for a bonding pressure of $10 \mathrm{MPa}$, together with the experimental values for the corresponding single factor trials. Both functions predict that the shear strength increases with increasing sintering time where the rate of increase decreases progressively. Under the different sintering temperatures, a sharp increase in shear strength occurs for the initial 3 to $5 \mathrm{~s}$, whereas no discernable increase in shear strength is observed for a sintering time longer than $8 \mathrm{~s}$. The values predicted from both functions have comparable agreement with the experimental values of the corresponding single factor trials.

For the kinetic-like equation, Eq. (5), the exponent of sintering time $(0.14)$ for the bonding strength is close to that for grain boundary/molten channel controlled growth of intermetallic compounds in interfacial reactions between liquid Sn-based solders and a $\mathrm{Ni}$ substrate [40]. Therefore, it is reasonable to assume that the bonding strength is more associated with grain boundary diffusion of silver nanoparticles during the time-reduced sintering process. This is because the true bonding area between the surface silver metallization of the substrate and the silver nanoparticles is far lower than $100 \%$, and also depends on the roughness of the bonding area of the substrate. An increase in the true bonding area due to grain boundary diffusion may cause an increase in the bonding strength than densification of the sintered silver layer alone. The strength of the sintered layer dependence on the densification is assumed to be controlled by surface-melting and/or plastic flow of silver nanoparticles as mentioned previously. This can be further supported by the fact that the grain size in the sintered die attachment produced within a shorter sintering time is almost equivalent to one produced within a prolonged sintering time, see Fig. 8. 

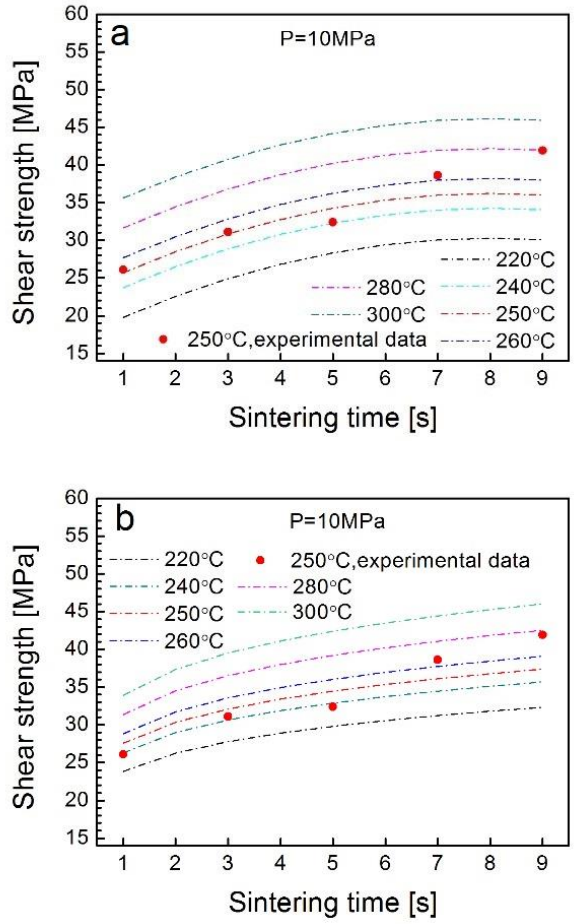

Fig. 7. Plots of average shear strength versus sintering time predicted from the second-order polynomial equation (4) for the bonding pressure of $10 \mathrm{MPa}$ (a), and the kinetic-like equation (5) for the bonding pressure of $10 \mathrm{MPa}(\mathrm{b})$, together with the experimental points of the corresponding single factor trials.
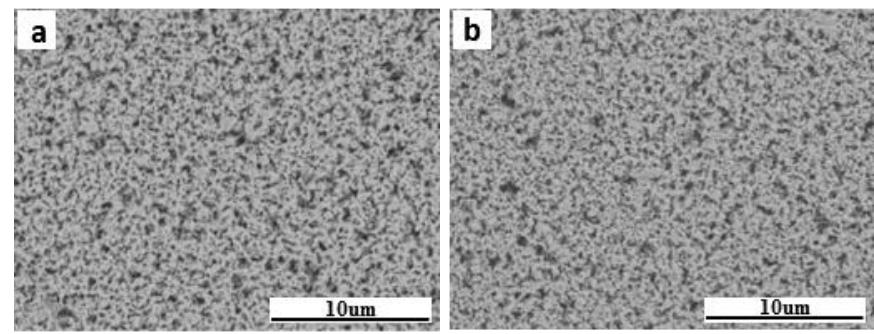

Fig. 8. SEM images of fracture surfaces after shear test taken from the samples of: (a) trial t1 with a sintering time of $1 \mathrm{~s}$; and (b) trial t 4 with $9 \mathrm{~s}$.

\subsection{Effect of Bonding Pressure}

Figure 9 presents the effect of bonding pressure on the shear strength derived from the second-order polynomial equation, (4), and the kinetic-like equation, Eq. (5), under different sintering times at a sintering temperature of $250{ }^{\circ} \mathrm{C}$, together with the experimental values of the corresponding single factor trials. Both functions predict increases in shear strength with increasing bonding pressure, albeit with slightly differing trends. The possible reason is the effect of substrate roughness on the shear strength when bonding pressure is increasing. As far as the authors are aware there have been no functions similar to the kinetic-like equations, Eq. (2) or Eq. (5), established in the present work describing the effects of external pressure on the kinetics of the sintering process reported in existing literature. The present results indicate the plastic flow of silver nanoparticles could contribute to the promotion of both densification and shear strength in a similar way. As shown in Fig. 10, with increasing sintering pressure, the microstructure of sintered die attachment appears to be denser but the grain size remains almost constant.
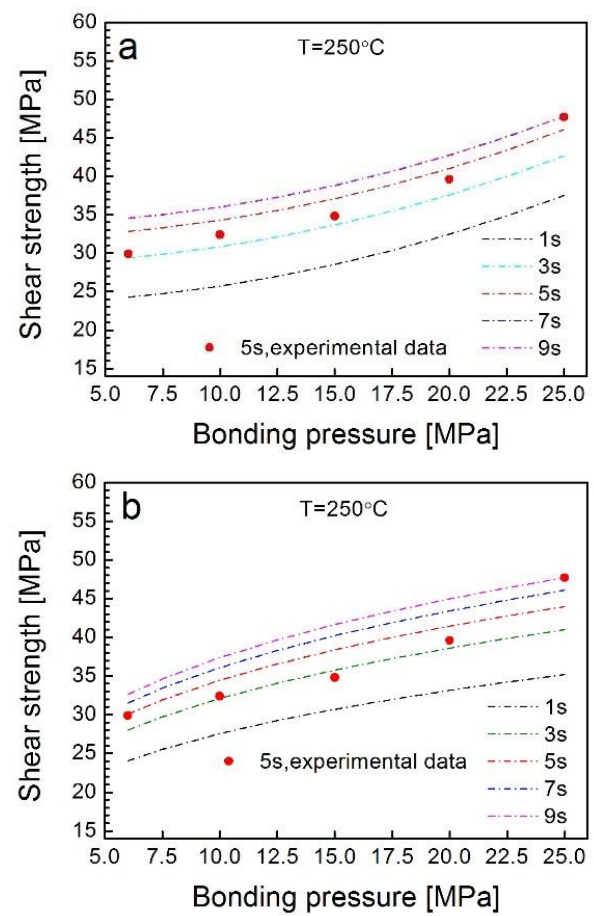

Fig. 9. Plots of average shear strength versus bonding pressure predicted from the second-order polynomial equation (4) for the sintering temperature of $250{ }^{\circ} \mathrm{C}$ (a), and the kinetic-like equation (5) for the sintering temperature of $250{ }^{\circ} \mathrm{C}(\mathrm{b})$, together with the experimental points of the corresponding single factor trials.

\subsection{Manufacturability of Time-reduced Sintering}

The manufacturability of sintering processes can be measured by the convenience and availability of implementing sintering parameters, i.e. the sintering temperature, pressure and time. With the recent development of automatic die pickup and placement systems, the application of sintering can be carried out (semi) automatically, overcoming limits of conventional sintering processes. However, the manufacturability for the sintering process needs to be identified prior to the actual sintering practice. A combination of a sufficient low bonding pressure $(<10 \mathrm{MPa})$, low sintering temperature $\left(<240{ }^{\circ} \mathrm{C}\right)$ and $/$ or short sintering times (within several seconds) is preferable for an efficient sintering process design. Furthermore, a processing window can help to identify the reliability of sintered joints prepared by specific sintering parameters. The relationship between shear strength and reliability of sintered joints prepared by time-reduced sintering will be reported in a future study.

\subsubsection{Low Bonding Pressure Application}

The second-order polynomial equation for shear strength, Eq. (4) is used to evaluate the manufacturability of sintering parameters of the time-reduced sintering. According to Eq. (4), high sintering temperatures $\left(\leq 300{ }^{\circ} \mathrm{C}\right)$ and/or long sintering times $(\leq 9 \mathrm{~s})$ are required when a bonding pressure as low as 6 $\mathrm{MPa}$ is employed to make robust bonds (joints with higher shear strength). Table II displays the sintering temperature and 
time required for obtaining sintered joints with a specific shear strength $(\mathrm{F})$ in different levels: L1 is less than $20 \mathrm{MPa}(\mathrm{F}<$ $20 \mathrm{MPa})$; $\mathrm{L} 2$ is between 20 and $30 \mathrm{MPa}(20 \mathrm{MPa} \leq \mathrm{F}<30 \mathrm{MPa})$; L3 is between 30 and $40 \mathrm{MPa}(30 \mathrm{MPa} \leq \mathrm{F}<40 \mathrm{MPa})$ and $\mathrm{L} 4$ is above $40 \mathrm{MPa}(\mathrm{F} \geq 40 \mathrm{MPa})$. The combinations of sintering parameters which could achieve a bonding strength of L1, L2, L3 or L4 are marked in green, yellow, blue and pink, respectively. Thus, the manufacturability of the time-reduced sintering with a fixed low bonding pressure of $6 \mathrm{MPa}$ can be evaluated by four shear strength levels, L1, L2, L3 and L4. In this case, the sintering process can easily be selected with respect to specific manufacturing conditions and/or requirements. For example, for a low assembly temperaturerequired application, a sintering time longer than $2 \mathrm{~s}$ is required for sintering at $220{ }^{\circ} \mathrm{C}$ under $6 \mathrm{MPa}$, where sintered joints with shear strengths between 20 and $30 \mathrm{MPa}$ may be obtained.

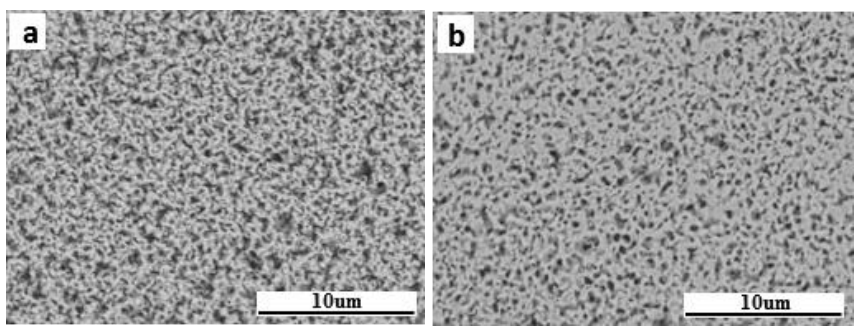

Fig. 10. SEM images of fracture surfaces after shear test taken from the samples of: (a) trial P1 under $6 \mathrm{MPa}$; and (b) trial P4 under $25 \mathrm{MPa}$.

\subsubsection{Low Sintering Temperature Application}

In the packaging of power semiconductors, several die attachment technologies may be required to complete one power module assembly. A low temperature sintering process is compatible with solder-reflow processes which typically have a maximum reflow temperature around $240{ }^{\circ} \mathrm{C}$ and it can therefore be applied before the solder-reflow process. This is because the sintered joints with high re-melt temperatures can withstand the subsequent solder reflow process. Additionally, low temperature sintering is desirable to reduce the thermomechanical stresses caused by the mismatch of CTEs between the different layers/materials within the whole module. Table III lists the processing window for low temperature $\left(220^{\circ} \mathrm{C}\right)$ time-reduced sintering for a wide range of bonding pressures to produce sintered joints with bonding strengths of 20 to $40 \mathrm{MPa}$. Here, the pressures are divided into three ranges: low pressure range $(\mathrm{P} \leq 10 \mathrm{MPa})$, medium pressure range $(10 \mathrm{MPa}<\mathrm{P} \leq 17.5$ $\mathrm{MPa}$ ) and high pressure range (17.5 $\mathrm{MPa}<\mathrm{P} \leq 25 \mathrm{MPa})$. For example, in order to obtain sintered joints with a shear strength above $30 \mathrm{MPa}$, a bonding pressure of high than $10 \mathrm{MPa}$ together with a sintering time longer than $8 \mathrm{~s}$ would be sufficient.

\subsubsection{Short Sintering Time Application}

In the present work, a time reduced sintering process has been investigated using a dry nanosilver film on an industrystandard die bonder with resulting sintered joints possessing bonding strengths of 20 to $54 \mathrm{MPa}$. Table IV lists the processing window for a time-reduced sintering process where very short sintering times of $5 \mathrm{~s}$ are compared. Using a sintering time of 5 $\mathrm{s}$, sintered joints with bonding strengths of 20 to $30 \mathrm{MPa}$ can be achieved by using sintering temperatures less than $230{ }^{\circ} \mathrm{C}$ and bonding pressures less than $15 \mathrm{MPa}$; sintered joints with bonding strengths between $30 \mathrm{MPa}$ and $40 \mathrm{MPa}$ can be produced by using sintering temperatures lower than $290^{\circ} \mathrm{C}$ and bonding pressures less than $25 \mathrm{MPa}$.

TABLE II PROCESSING WINDOW OF TIME-REDUCED SINTERING PROCESS WHEN THE BONDING PRESSURE IS 6 MPA.

\begin{tabular}{|c|c|c|c|c|c|c|c|c|c|}
\hline & \multicolumn{3}{|c|}{ Low temperature } & \multicolumn{3}{|c|}{ Medium temperature } & \multicolumn{3}{|c|}{ High temperature } \\
\hline & $220^{\circ} \mathrm{C}$ & $230^{\circ} \mathrm{C}$ & $240^{\circ} \mathrm{C}$ & $250^{\circ} \mathrm{C}$ & $260^{\circ} \mathrm{C}$ & $270^{\circ} \mathrm{C}$ & $280^{\circ} \mathrm{C}$ & $290^{\circ} \mathrm{C}$ & $300^{\circ} \mathrm{C}$ \\
\hline $1 \mathrm{~s}$ & L1 & L2 & L2 & L2 & L2 & L2 & L3 & L3 & L3 \\
\hline $2 \mathrm{~s}$ & L2 & $\mathrm{L} 2$ & L2 & L2 & L2 & L3 & L3 & L3 & L3 \\
\hline $3 \mathrm{~s}$ & L2 & L2 & L2 & L2 & L3 & L3 & L3 & L3 & L3 \\
\hline $4 \mathrm{~s}$ & L2 & L2 & L2 & L3 & L3 & L3 & L3 & L3 & $\mathrm{L} 4$ \\
\hline $5 s$ & L2 & L2 & L3 & L3 & L3 & L3 & L3 & $\mathrm{L} 4$ & $\mathrm{~L} 4$ \\
\hline $6 s$ & L2 & L2 & L3 & L3 & L3 & L3 & L3 & $\mathrm{L} 4$ & $\mathrm{~L} 4$ \\
\hline $7 \mathrm{~s}$ & L2 & L3 & L3 & L3 & L3 & L3 & $\mathrm{L} 4$ & $\mathrm{~L} 4$ & $\mathrm{~L} 4$ \\
\hline $8 \mathrm{~s}$ & L2 & L3 & L3 & L3 & L3 & L3 & L4 & $\mathrm{L} 4$ & $\mathrm{~L} 4$ \\
\hline $9 \mathrm{~s}$ & L2 & L3 & L3 & L3 & L3 & L3 & $\mathrm{L} 4$ & $\mathrm{~L} 4$ & $\mathrm{~L} 4$ \\
\hline
\end{tabular}

L1 $(\mathrm{F}<20 \mathrm{MPa}), \mathrm{L} 2(20 \mathrm{MPa} \leq \mathrm{F}<30 \mathrm{MPa}) ; \mathrm{L} 3(30 \mathrm{MPa} \leq \mathrm{F}<40 \mathrm{MPa})$, and $\mathrm{L} 4(\mathrm{~F} \geq 40 \mathrm{MPa})$.

TABLE III PROCESSING WINDOW OF TIME-REDUCED SINTERING PROCESSES WHEN THE SINTERING TEMPERATURE IS $220{ }^{\circ} \mathrm{C}$.

\begin{tabular}{|c|c|c|c|c|c|c|c|c|c|}
\hline & \multicolumn{3}{|c|}{ Low pressure } & \multicolumn{3}{|c|}{ Medium pressure } & \multicolumn{3}{|c|}{ High pressure } \\
\hline & $6.0 \mathrm{MPa}$ & $7.5 \mathrm{MPa}$ & $10.0 \mathrm{MPa}$ & $12.5 \mathrm{MPa}$ & $15.0 \mathrm{MPa}$ & $17.5 \mathrm{MPa}$ & $20.0 \mathrm{MPa}$ & $22.5 \mathrm{MPa}$ & $25.0 \mathrm{MPa}$ \\
\hline $1 \mathrm{~s}$ & L1 & L1 & L1 & L2 & L2 & L2 & L2 & L2 & L3 \\
\hline $2 \mathrm{~s}$ & L2 & L2 & L2 & L2 & $\mathrm{L} 2$ & L2 & L2 & L3 & L3 \\
\hline $3 \mathrm{~s}$ & L2 & L2 & L2 & L2 & $\mathrm{L} 2$ & L2 & L3 & L3 & L3 \\
\hline $4 s$ & $\mathrm{~L} 2$ & L2 & L2 & $\mathrm{L} 2$ & $\mathrm{~L} 2$ & L3 & L3 & L3 & L3 \\
\hline $5 s$ & L2 & L2 & L2 & L2 & L3 & L3 & L3 & L3 & $\mathrm{L} 4$ \\
\hline $6 s$ & L2 & L2 & L2 & L3 & L3 & L3 & L3 & L3 & $\mathrm{L} 4$ \\
\hline $7 \mathrm{~s}$ & L2 & L2 & L2 & L3 & L3 & L3 & L3 & L3 & $\mathrm{L} 4$ \\
\hline $8 \mathrm{~s}$ & L2 & L2 & L3 & L3 & L3 & L3 & L3 & L3 & $\mathrm{L} 4$ \\
\hline $9 s$ & L2 & L2 & L3 & L3 & L3 & L3 & L3 & L3 & L4 \\
\hline
\end{tabular}

L1 (F<20MPa), L2 (20MPa $\leq \mathrm{F}<30 \mathrm{MPa}) ; \mathrm{L} 3(30 \mathrm{MPa} \leq \mathrm{F}<40 \mathrm{MPa})$, and L4 $(\mathrm{F} \geq 40 \mathrm{MPa})$. 
TABLE IV PROCESSING WINDOW OF TIME-REDUCED SINTERING PROCESSES WHEN THE SINTERING TIME IS $5 \mathrm{~S}$.

\begin{tabular}{|c|c|c|c|c|c|c|c|c|c|c|}
\hline & & \multicolumn{3}{|c|}{ Low temperature } & \multicolumn{3}{|c|}{ Medium temperature } & \multicolumn{3}{|c|}{ High temperature } \\
\hline & & $220^{\circ} \mathrm{C}$ & $230^{\circ} \mathrm{C}$ & $240^{\circ} \mathrm{C}$ & $250^{\circ} \mathrm{C}$ & $260^{\circ} \mathrm{C}$ & $270^{\circ} \mathrm{C}$ & $280^{\circ} \mathrm{C}$ & $290^{\circ} \mathrm{C}$ & $300^{\circ} \mathrm{C}$ \\
\hline \multirow{2}{*}{ Low pressure } & $6.0 \mathrm{MPa}$ & L2 & L2 & L3 & L3 & L3 & L3 & L3 & L4 & $\mathrm{L} 4$ \\
\hline & $7.5 \mathrm{MPa}$ & $\mathrm{L} 2$ & L2 & L3 & L3 & L3 & L3 & L3 & L4 & L4 \\
\hline \multirow{3}{*}{ Medium pressure } & $12.5 \mathrm{MPa}$ & L2 & L3 & L3 & L3 & L3 & L3 & $\mathrm{L} 4$ & $\mathrm{~L} 4$ & $\mathrm{~L} 4$ \\
\hline & $15.0 \mathrm{MPa}$ & L3 & L3 & L3 & L3 & L3 & L4 & L4 & L4 & L4 \\
\hline & $17.5 \mathrm{MPa}$ & L3 & L3 & L3 & L4 & L4 & $\mathrm{L} 4$ & L4 & L4 & $\mathrm{L} 4$ \\
\hline High pressure & $25.0 \mathrm{MPa}$ & L4 & L4 & L4 & L4 & L4 & L4 & L4 & L4 & L4 \\
\hline
\end{tabular}

L1 $(\mathrm{F}<20 \mathrm{MPa})$, L2 $(20 \mathrm{MPa} \leq \mathrm{F}<30 \mathrm{MPa}) ; \mathrm{L} 3(30 \mathrm{MPa} \leq \mathrm{F}<40 \mathrm{MPa})$, and L4 $(\mathrm{F} \geq 40 \mathrm{MPa})$.

\section{CONCLUSIONS}

This study investigates sintering parameters for a timereduced sintering process for dry nanosilver film using statistical experiment design methodology. Shear strength values were analyzed using both second-order polynomial and kinetic-like equations to describe the effects of sintering temperature, time and pressure. According to the kinetic-like equation for shear strength, the shear strength is mainly associated with grain boundary diffusion, especially the silver diffusion between the sintered layer and the silver metallization on the substrate. On the other hand, a second-order polynomial

\section{REFERENCES}

[1] P. O. Quintero and F. P. McCluskey, "Temperature cycling reliability of high-temperature lead-free dieattach technologies," Device and Materials Reliability, IEEE Transactions on, vol. 11, no. 4, pp. 531-539, 2011.

[2] S. Tabatabaei, A. Kumar, H. Ardebili, P. J. Loos, and P. M. Ajayan, "Synthesis of $\mathrm{Au}-\mathrm{Sn}$ alloy nanoparticles for lead-free electronics with unique combination of low and high melting temperatures," Microelectronics Reliability, vol. 52, no. 11, pp. 2685-2689, 11// 2012.

[3] T. Shimizu, H. Ishikawa, I. Ohnuma, and K. Ishida, "ZnAl-Mg-Ga alloys as Pb-free solder for die-attaching use," Journal of electronic materials, vol. 28, no. 11, pp. 1172$1175,1999$.

[4] J. Dai, J. Li, P. Agyakwa, M. Corfield, and C. M. Johnson, "Comparative thermal and structural characterization of sintered nano-silver and high-lead solder die attachments during power cycling," IEEE Transactions on Device and Materials Reliability, 2018.

[5] H. Schwarzbauer and R. Kuhnert, "Novel large area joining technique for improved power device performance," in Industry Applications Society Annual Meeting, 1989., Conference Record of the 1989 IEEE, 1989: IEEE, pp. 1348-1351.

[6] H. Schwarzbauer, "Method of securing electronic components to a substrate," ed: Google Patents, 1989.

[7] Z. Zhang and G.-Q. Lu, "Pressure-assisted lowtemperature sintering of silver paste as an alternative dieattach solution to solder reflow," IEEE Transactions on electronics packaging manufacturing, vol. 25, no. 4, pp. 279-283, 2002.

[8] Y. Mei, Y. Cao, G. Chen, X. Li, G.-Q. Lu, and X. Chen, "Rapid sintering nanosilver joint by pulse current for power electronics packaging," IEEE Transactions on Device and Materials Reliability, vol. 13, no. 1, pp. 258265, 2013. equation with higher prediction accuracy can predict the shear strength dependency on the sintering temperature, time and pressure. It was further used to draw processing windows for the time-reduced sintering and identify manufacturability requirements for sintered joints with specific shear strengths.

\section{ACKNOWLEDGEMENT}

This work was supported by the U.K. Engineering and Physical Sciences Research Council through the Centre for Power Electronics under Grant EP/K 035304/1. The authors would like to thank Oscar Khaselev and Mike Marczi of Alpha Assembly Solutions for providing nanosilver film.

[9] K. Xiao, J. N. Calata, H. Zheng, K. D. Ngo, and G.-Q. Lu, "Simplification of the nanosilver sintering process for large-area semiconductor chip bonding: reduction of hotpressing temperature below 200/spl deg/C," IEEE Transactions on Components, Packaging and Manufacturing Technology, vol. 3, no. 8, pp. 1271-1278, 2013.

[10] Y. Mei, G. Chen, Y. Cao, X. Li, D. Han, and X. Chen, "Simplification of low-temperature sintering nanosilver for power electronics packaging," Journal of electronic materials, vol. 42, no. 6, pp. 1209-1218, 2013.

[11] K. S. Siow, "Mechanical properties of nano-silver joints as die attach materials," Journal of alloys and compounds, vol. 514, pp. 6-19, 2012.

[12] Y. Akada, H. Tatsumi, T. Yamaguchi, A. Hirose, T. Morita, and E. Ide, "Interfacial bonding mechanism using silver metallo-organic nanoparticles to bulk metals and observation of sintering behavior," Materials transactions, vol. 49, no. 7, pp. 1537-1545, 2008.

[13] A. A. Wereszczak, D. J. Vuono, L. Zhenxian, and E. E. Fox, "Sintered silver Joint strength dependence on substrate topography and attachment pad geometry," in Integrated Power Electronics Systems (CIPS), 2012 7th International Conference on, 2012, pp. 1-6.

[14] C. Buttay et al., "Die attach of power devices using silver sintering - bonding process optimization and characterization," in High Temperature Electronics Network (HiTEN), Oxford, United Kingdom, 2011, pp. 17.

[15] M. Knoerr, S. Kraft, and A. Schletz, "Reliability assessment of sintered nano-silver die attachment for power semiconductors," in 2010 12th Electronics Packaging Technology Conference, 2010: IEEE, pp. 5661.

[16] S. Fu, Y. Mei, X. Li, P. Ning, and G.-Q. Lu, "Parametric study on pressureless sintering of nanosilver paste to bond large-area $(\geqslant 100 \mathrm{~mm} 2)$ power chips at low 
temperatures for electronic packaging," Journal of Electronic Materials, vol. 44, no. 10, pp. 3973-3984, 2015.

[17] W. Schmitt, S. Fritzsche, and M. Thomas, "Sinter materials for broad process windows in DCB packagesconcepts and results," in Integrated Power Electronics Systems (CIPS), 2012 7th International Conference on, 2012: IEEE, pp. 1-6.

[18] J. Li, C. M. Johnson, C. Buttay, W. Sabbah, and S. Azzopardi, "Bonding strength of multiple SiC die attachment prepared by sintering of Ag nanoparticles," Journal of Materials Processing Technology, vol. 215, pp. 299-308, 2015.

[19] J. Dai, J. Li, P. Agyakwa, and C. M. Johnson, "Power cycling reliability of time-reduced sintering for attaching $\mathrm{SiC}$ diodes using nanosilver film," in CIPS 2018; 10th International Conference on Integrated Power Electronics Systems, 2018: VDE, pp. 1-6.

[20] K.-T. Fang, D. K. Lin, P. Winker, and Y. Zhang, "Uniform design: theory and application," Technometrics, vol. 42, no. 3, pp. 237-248, 2000.

[21] M.-Y. Xie and K.-T. Fang, "Admissibility and minimaxity of the uniform design measure in nonparametric regression model," Journal of statistical planning and inference, vol. 83, no. 1, pp. 101-111, 2000.

[22] F. J. Hickernell and M. Q. Liu, "Uniform designs limit aliasing," Biometrika, vol. 89, no. 4, pp. 893-904, 2002.

[23] N. R. Draper and H. Smith, "Applied Regression Analysis, John Wiley and Sons," New York, vol. 407, 1981.

[24] R. Christensen, Analysis of variance, design, and regression: applied statistical methods. CRC Press, 1996.

[25] R. E. Walpole, R. H. Myers, S. L. Myers, and K. Ye, Probability and statistics for engineers and scientists. Macmillan New York, 1993.

[26] D. L. Johnson and I. B. Cutler, "Diffusion sintering: II, initial sintering kinetics of alumina," Journal of the American Ceramic Society, vol. 46, no. 11, pp. 545-550, 1963.

[27] P. L. Chen and I. W. Chen, "Sintering of fine oxide powders: II, sintering mechanisms," Journal of the American Ceramic Society, vol. 80, no. 3, pp. 637-645, 1997.

[28] J. Dai, J. Li, P. Agyakwa, and C. M. Johnson, "Timeefficient sintering processes to attach power devices using nanosilver dry film," Journal of Microelectronics and Electronic Packaging, vol. 14, no. 4, pp. 140-149, 2017.

[29] J. Dai, "Process and Reliability of Die Attachment by Time-Reduced Sintering of Nanosilver Film," University of Nottingham, 2019.

[30] L. A. Navarro et al., "Thermomechanical assessment of die-attach materials for wide bandgap semiconductor devices and harsh environment applications," IEEE transactions on Power Electronics, vol. 29, no. 5, pp. 2261-2271, 2014.

[31] J. Yan et al., "Pressureless bonding process using Ag nanoparticle paste for flexible electronics packaging," Scripta Materialia, vol. 66, no. 8, pp. 582-585, 2012.

[32] M. Knoerr and A. Schletz, "Power semiconductor joining through sintering of silver nanoparticles: evaluation of influence of parameters time, temperature and pressure on density, strength and reliability," in Integrated Power Electronics Systems (CIPS), 2010 6th International Conference on, 2010: IEEE, pp. 1-6.

[33] E. Ide, S. Angata, A. Hirose, and K. F. Kobayashi, "Metal-metal bonding process using Ag metallo-organic nanoparticles," Acta Materialia, vol. 53, no. 8, pp. 23852393, 2005.

[34] Y. Shi, W. Fang, Z. Xia, Y. Lei, F. Guo, and X. Li, "Investigation of rare earth-doped $\mathrm{BiAg}$ high-temperature solders," Journal of Materials Science: Materials in Electronics, vol. 21, no. 9, pp. 875-881, 2010.

[35] S. Egelkraut, L. Frey, M. Knoerr, and A. Schletz, "Evolution of shear strength and microstructure of die bonding technologies for high temperature applications during thermal aging," in Electronics Packaging Technology Conference (EPTC), 2010 12th, 2010: IEEE, pp. 660-667.

[36] R. Hoffman and D. Turnbull, "Lattice and Grain Boundary Self - Diffusion in Silver," Journal of Applied Physics, vol. 22, no. 5, pp. 634-639, 1951.

[37] A. Sobaszek, "MEASUREMENT OF THE GRAINBOUNDARY SELF-DIFFUSION COEFFICIENT IN SILVER," Nukleonika, vol. 13, no. 3, pp. 279-288, 1968.

[38] C. Smithells, "Equilibrium Diagrams," Metals Reference Book, 6th edn. Butterworth \& Co Ltd., London, 1983.

[39] L. A. Pérez - Maqueda, J. M. Criado, and C. Real, "Kinetics of the initial stage of sintering from shrinkage data: simultaneous determination of activation energy and kinetic model from a single nonisothermal experiment," Journal of the American Ceramic Society, vol. 85, no. 4, pp. 763-768, 2002.

[40] G. Ghosh, "Coarsening kinetics of Ni 3 Sn 4 scallops during interfacial reaction between liquid eutectic solders and $\mathrm{Cu} / \mathrm{Ni} / \mathrm{Pd}$ metallization," Journal of Applied Physics, vol. 88, no. 11, pp. 6887-6896, 2000.

[41] C. Ma and R. Swalin, "Self - Diffusion in Liquid Tin," The Journal of Chemical Physics, vol. 36, no. 11, pp. 3014-3018, 1962.

[42] G. Careri, A. Paoletti, and M. Vicentini, "Further experiments on liquid indium and tin self-diffusion," $\mathrm{Il}$ Nuovo Cimento (1955-1965), vol. 10, no. 6, p. 1088, 1958.

[43] T. Bachels, H.-J. Güntherodt, and R. Schäfer, "Melting of isolated tin nanoparticles," Physical Review Letters, vol. 85 , no. 6, p. $1250,2000$.

[44] T. Malow and C. Koch, "Grain growth in nanocrystalline iron prepared by mechanical attrition," Acta Materialia, vol. 45, no. 5, pp. 2177-2186, 1997.

[45] N. B. Bell, C. B. DiAntonio, and D. B. Dimos, "Development of conductivity in low conversion temperature silver pastes via addition of nanoparticles," Journal of materials research, vol. 17, no. 9, pp. 24232432, 2002.

[46] M. Ashby, "A first report on sintering diagrams," Acta Metallurgica, vol. 22, no. 3, pp. 275-289, 1974.

[47] S. J. L. Kang, Sintering: densification, grain growth and microstructure. Butterworth-Heinemann, 2004. 